\title{
Back to the root: a large animal model of the Ross procedure
}

\author{
Lucas Van Hoof ${ }^{1,2}$, Piet Claus ${ }^{3}$, Elizabeth A. V. Jones ${ }^{4}$, Bart Meuris ${ }^{1,2}$, Nele Famaey ${ }^{5}$, Peter Verbrugghe ${ }^{1,2 \#}$, \\ Filip Rega ${ }^{1,2 \#}$
}

${ }^{1}$ Department of Cardiac Surgery, University Hospitals Leuven, Leuven, Belgium; ${ }^{2}$ Experimental Cardiac Surgery, KU Leuven, Leuven, Belgium; ${ }^{3}$ Cardiovascular Imaging and Dynamics, KU Leuven, Leuven, Belgium; ${ }^{4}$ Center for Molecular and Vascular Biology, KU Leuven, Leuven, Belgium; ${ }^{5}$ Biomechanics Section, KU Leuven, Leuven, Belgium

\#These authors contributed equally to this work.

Correspondence to: Lucas Van Hoof, MD. Department of Cardiac Surgery, University Hospitals Leuven, Herestraat 49, 3000 Leuven, Belgium.

Email: lucas.vanhoof@kuleuven.be.

\begin{abstract}
The excellent clinical outcomes of the Ross procedure and previous histological studies suggest that the pulmonary autograft has the potential to offer young patients a permanent solution to aortic valve disease. We aim to study the early mechanobiological adaptation of the autograft. To this end, we have reviewed relevant existing animal models, including the canine models which enabled Donald N Ross to perform the first Ross procedure in a patient in 1967. Two research groups recently evaluated the isolated effect of systemic pressures on pulmonary arterial tissue in an ovine model of a pulmonary artery interposition graft in the descending aorta. While this model is ideal to study the artery's biological response and the effect of external support, it does not recreate the complex environment of the aortic root. The freestanding Ross procedure has been performed in pigs and sheep before. These studies offered valuable insights into leaflet growth and histological remodeling, yet may be less relevant to adults undergoing the Ross procedure, as pronounced autograft dilatation was achieved by using small, rapidly growing animals. Therefore, a large animal model remains needed to determine the ideal conditions and surgical technique to ensure longterm autograft remodeling and valve function. We set out to develop an ovine model of the Ross procedure performed as a freestanding root replacement, acknowledging that the sheep's specific anatomy and the setting of an animal laboratory would mandate several modifications in surgical strategy. This article describes the development, surgical technique and early outcomes of our animal model while highlighting opportunities for further research.
\end{abstract}

Keywords: Ross procedure; sheep; ovine; model

Submitted Sep 25, 2020. Accepted for publication Mar 29, 2021.

doi: 10.21037/acs-2020-rp-21

View this article at: http://dx.doi.org/10.21037/acs-2020-rp-21

\section{Introduction}

The search for a living aortic valve substitute was prompted in the 1960's by the limited durability and lack of growth potential of aortic homografts, and by the thrombo-embolic complications with the first prosthetic valves (1). Based on canine feasibility experiments by the group of Shumway, the Ross procedure was first performed in a patient in 1967 (2-4). Even nowadays, the Ross procedure offers the only aortic valve substitute that can restore a patient's longterm survival and quality-of-life to that of a healthy, aged- matched population (5-7). Commonly voiced concerns include a higher operative risk in low-volume centers, the fear of complex reoperations on two valves and the risk of pulmonary autograft dilatation when performed as a freestanding root replacement (8).

The observation that many patients have a wellfunctioning pulmonary autograft several decades after the Ross procedure demonstrates the pulmonary root's ability to remodel when exposed to systemic conditions (9-13). Nonetheless, optimal, patient-specific autograft geometry 


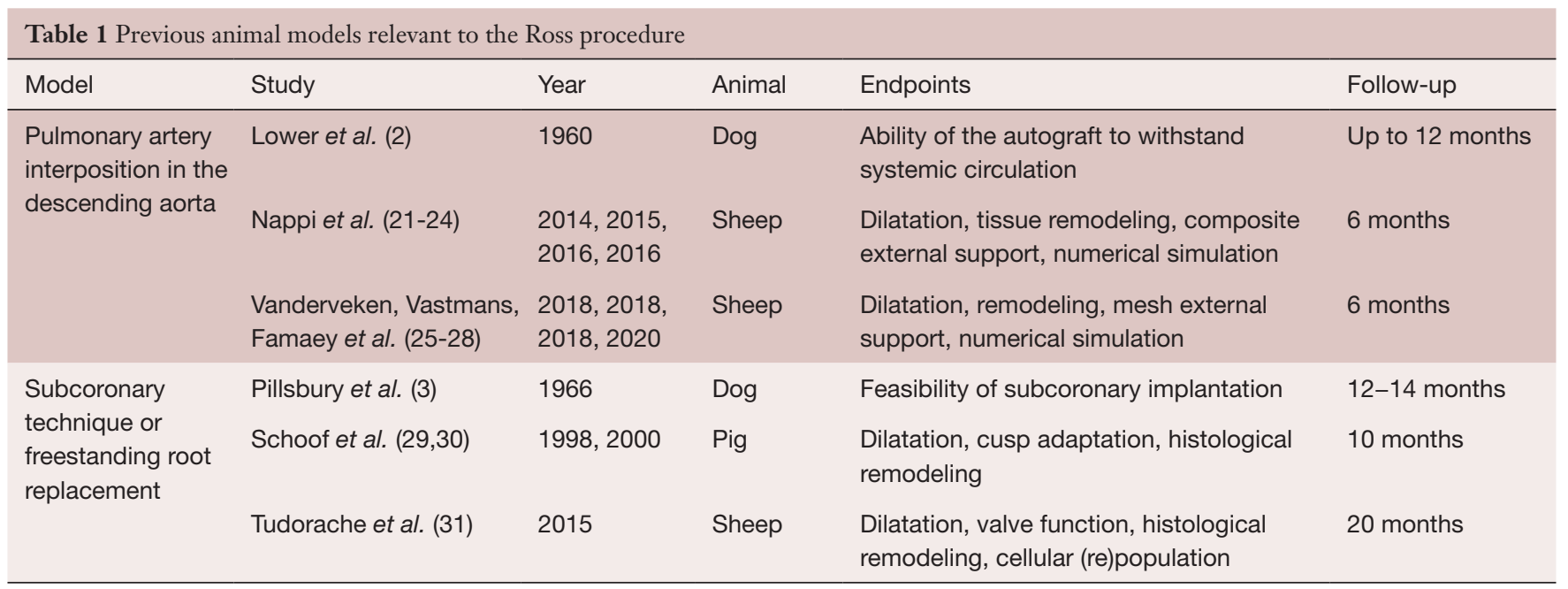

and surgical technique that ensures long-term valve competence is insufficiently understood. Prosthetic external support is a commonly used strategy aimed at preventing autograft dilatation. Yet, the effect on reoperation rate, valve function and mechanical remodeling is uncertain (7). Furthermore, opportunities to study well-remodeled autograft leaflets have been limited, both in clinical and experimental research.

As the pulmonary autograft has the potential to become a permanent aortic valve substitute, a large animal model remains necessary to address these remaining questions and determine the ideal conditions for autograft remodeling. This paper reviews existing animal models of the Ross procedure and describes the development and technical aspects of our ovine model of the freestanding Ross while highlighting opportunities for further research.

\section{Existing animal models of the Ross procedure}

The use of large animals has been indispensable to the development of cardiopulmonary bypass (CPB) and contemporary surgical techniques (14). The group of Shumway first evaluated the ability of the pulmonary root to withstand the systemic circulation using a canine model of pulmonary valve autotransplantation into the descending aorta (2). After the technical feasibility of subcoronary autograft implantation was later confirmed in dogs, Donald $\mathrm{N}$ Ross reported the first clinical pulmonary autograft procedure in $1967(1,3,4)$. While the surgical technique of mitral valve replacement using a pulmonary autograft has also been evaluated in animal models, this is beyond the scope of this report $(15,16)$.

Nowadays, sheep (Ovis aries) are the most commonly used animal for preclinical evaluation of heart valve substitutes, primarily because of the similarities in cardiovascular anatomy and physiology to humans (17). Furthermore, they are known for their rapid postoperative recovery, ease of establishing vascular access, moderate weight gain and docile nature, facilitating perioperative care and follow-up investigations $(18,19)$. As the ratio between mean systemic and pulmonary arterial pressures (75-100 $\mathrm{mmHg}$ and $15-17 \mathrm{mmHg}$ in sheep, respectively) in sheep is similar to that in humans, a comparable relative increase in autograft diameter and wall stress can be expected $(19,20)$. While the cardiac biology of pigs and dogs is more similar to that of humans, pigs are difficult to handle and notorious for their challenging perioperative management. Dogs, on the other hand, fell out of favor due to moral concerns and protest by the anti-vivisectionist movement (19).

An overview of previous animal models studying the Ross procedure is shown in Table 1 and discussed in Video 1 . To evaluate the isolated effect of systemic pressures on pulmonary arterial tissue, the authors have previously implanted a segment of the main pulmonary artery in the descending aorta of sheep, with and without external support by a porous mesh (28). In a similar animal model, Nappi et al. investigated the effect of a composite, partially resorbable external support on autograft dilatation and histological adaptation, with promising results (21-24). While these simplified animal models can be performed without arresting the heart or even $\mathrm{CPB}$, the pulmonary 
autograft is not exposed to the demanding hemodynamic environment of the aortic root with its dynamic annulus, unique flow pattern and longitudinal motion.

Only two other groups have performed the Ross procedure as a freestanding root replacement and published detailed results (29-31). In a porcine model with an operative technique very akin to ours, Schoof et al. performed a detailed evaluation of autograft dilatation, leaflet growth and histological remodeling in growing pigs $(29,30)$. While it must be commended that they performed a freestanding Ross procedure in piglets with an average weight of $25.4 \mathrm{~kg}$, they were confronted with several of the limitations of pigs. Due to the animals' sensitivity to stress and rapid weight gain to $143 \pm 37 \mathrm{~kg}$ (average $\pm \mathrm{SD}$ ), serial follow-up imaging was not performed. Furthermore, multiple pigs developed right ventricular failure due to progressive mismatch with the bioprosthesis or homograft used to reconstruct the pulmonary root $(29,30)$. In the longest experimental evaluation of the pulmonary autograft to date, Tudorache et al. compared the repopulation of decellularized aortic and pulmonary homografts with the cell distribution in pulmonary autografts after 20 months in lambs with an average weight of $25 \mathrm{~kg}$ at operation (31). The autograft remodeling observed in both of these studies may, however, be less relevant to adult patients undergoing the Ross procedure as pronounced dilatation was achieved by using small, rapidly growing animals $(29,31)$.

\section{Designing an animal model of the Ross procedure}

\section{Study design}

The primary goal of our underlying study was to evaluate early adaptation mechanisms in the pulmonary autograft which may influence long-term outcome. Therefore, we set out to perform the Ross procedure as a total root replacement with implantation of the autograft deep in the aortic annulus (32). For all operations, the lead surgeon was either FR or PV, who perform more than 25 Ross procedures per year at the University Hospitals Leuven. This study was approved by the Animal Ethics Committee at KU Leuven (project P014-2019). Female, yearling Swifter sheep were obtained from the university farm.

For the purpose of our study, a preoperative MRI was performed to provide reference dimensions of the aorta and pulmonary root. Animals undergo an MRIscan at 10-14 days, three and six months postoperatively to assess autograft dilatation and valve function. At six months, after MRI, transthoracic echocardiography and transdiaphragmatic echocardiography via a small laparotomy, sheep are sacrificed and autograft samples are collected for histology, protein analysis, mechanical testing and transcriptional analysis of genes related to extracellular matrix remodeling.

\section{Surgical technique}

Prior to surgery, animals are fasted for twenty-four hours. Sedation is achieved with intravenous ketamine $(4 \mathrm{mg} / \mathrm{kg})$ and anesthesia is induced (5\%) and maintained (1-3\%) with isoflurane inhalation. After intubation, an arterial line is placed in the right auricular artery, a central venous catheter is inserted in the right external jugular vein and antibiotic prophylaxis (penicillin $10.000 \mathrm{IE} / \mathrm{kg}$, gentamicin $7 \mathrm{mg} / \mathrm{kg}$ ) is administered. An orogastric tube is placed to prevent ruminal distension. Animals are positioned in the right lateral recumbent position, surgically scrubbed and draped to expose the left hemithorax and neck. Baseline activated clotting time (ACT) and blood gas are taken and repeated as indicated. A left thoracotomy is performed in the third intercostal space (Figure 1) and via a cervicotomy, the common carotid artery and external jugular vein are exposed. Lidocaine $(1.5 \mathrm{mg} / \mathrm{kg})$ is given to prevent ventricular arrhythmias.

After dissection of the aortopulmonary window and heparinization (300 IU $/ \mathrm{kg}$, target ACT > 500), normothermic cardiopulmonary bypass $(\mathrm{CPB})$ is established by cannulating the neck vessels, using a femoral arterial cannula (16F Fem-Flex, Edwards ${ }^{\circledR}$, Irvine, California, USA) and a multistage femoral venous cannula (24F VFEM Edwards ${ }^{\circledR}$ ). Phenylephrine $(1-3 \mu \mathrm{g} / \mathrm{kg} / \mathrm{min})$ is used as a vasoconstrictor during CPB with a target mean systemic blood pressure of $40-60 \mathrm{mmHg}$. Mechanical ventilation is stopped and isoflurane is administered via the oxygenator. A venting catheter (13F DLP ${ }^{\circledR}$, Medtronic, Minneapolis, MN, USA) is inserted into the left ventricle via the left atrial appendage and the distal pulmonary artery is snared and transected just proximal to its bifurcation. With upwards traction on the pulmonary artery, the autograft is harvested on the beating heart (Figure 1B) with careful dissection between the leftfacing sinus and the left main coronary artery.

Next, the aorta is cross-clamped and antegrade cold crystalloid cardioplegia is infused $(500-800 \mathrm{~mL}$, composition based on Plegisol ${ }^{\circledR}$, Abbott Laboratories, Chicago, Illinois, USA. $1.7 \mathrm{~g}$ bicarbonate and $120 \mathrm{mg}$ lidocaine added 

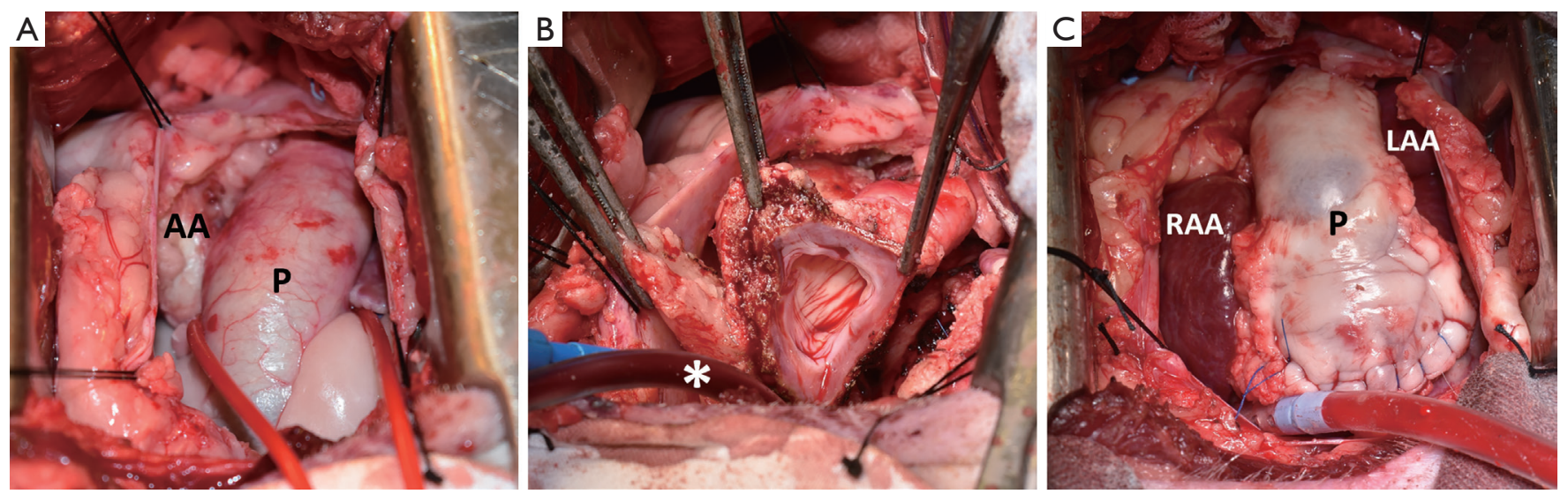

Figure 1 (A) Intraoperative view through left thoracotomy, providing optimal access to the pulmonary artery (P). The animal's head is on the left of the image. The aortic root is situated behind the pulmonary sinuses. (B) Harvesting the pulmonary autograft on the beating heart with a pericardial sump $\left(^{*}\right)$ placed in the right ventricle. $(\mathrm{C})$ View after implantation of the pulmonary homograft $(\mathrm{P})$. AA, ascending aorta; LAA, left atrial appendage; P, pulmonary artery/homograft; RAA, right atrial appendage.

per $1 \mathrm{~L})$. Cardioplegia is later repeated selectively $(150$ $\mathrm{mL}$ per coronary artery every $20-30$ minutes). After a low transection of the aorta, the leaflets are excised and coronary buttons mobilized (Figure $2 A$ ). The pulmonary autograft, trimmed of excess infundibular muscle, is sutured low into the aortic annulus using a continuous 4-0 polypropylene suture. The left-facing sinus of the autograft is placed in the left coronary sinus. After confirming integrity of the autograft leaflets and valve geometry, the coronary arteries are reimplanted using a 6-0 polypropylene suture. The autograft is trimmed to the desired length above the sinotubular junction and the distal anastomosis is completed with 5-0 polypropylene (Figure $2 B$ ). To reduce cross-clamp time and allow for evaluation of aortic root hemostasis, the cross-clamp is opened at this point, after deairing (Figure 2C). Next, the right ventricular outflow tract is reconstructed on the beating heart using a cryopreserved homograft, as shown in Figure 1C. The proximal and distal anastomoses are performed with 4-0 and 5-0 polypropylene, respectively.

After sufficient reperfusion, the sheep is weaned from CPB with vasopressor and inotropic support as indicated (phenylephrine $0.5-3 \mu \mathrm{g} / \mathrm{kg} / \mathrm{min}$, norepinephrine $0.2-$ $0.6 \mu \mathrm{g} / \mathrm{kg} / \mathrm{min}$, epinephrine in $10 \mu \mathrm{g}$ boluses). Protamine $(1 \mathrm{mg} / \mathrm{kg})$ is administered only in case of pronounced bleeding, as it can induce lethal pulmonary vasoconstriction, especially in sheep (19). The pericardium is left open and the chest is closed in a standard fashion with a pericardial drain in place. Once inotropic support can be ceased and the animals are awake and breathing spontaneously, they are extubated, transferred to the stable and the chest drain is removed. Meloxicam $(0.4 \mathrm{mg} / \mathrm{kg})$ and buprenorphine $(10 \mu \mathrm{g} / \mathrm{kg})$ are used for postoperative analgesia, while amoxicillin $(30 \mathrm{mg} / \mathrm{kg} / \mathrm{d})$, furosemide $(20 \mathrm{mg} / \mathrm{d})$ and enoxaparin $(40 \mathrm{mg} / \mathrm{d})$ are continued for seven days, or longer based on clinical indication. The Video 2 illustrates the operation's crucial steps.

\section{Pulmonary homograft preparation}

Sheep autopsied during unrelated experiments were used to make cryopreserved pulmonary homografts via a simplified protocol. Hearts were explanted and pulmonary roots dissected free under sterile conditions and placed in sterile containers with $0.9 \%$ sodium chloride $(\mathrm{NaCl})$ with $250 \mu \mathrm{g} / \mathrm{mL}$ ceftriaxone, $50 \mu \mathrm{g} / \mathrm{mL}$ vancomycin and $100 \mu \mathrm{g} / \mathrm{mL}$ polymyxin $\mathrm{B}$ at $4{ }^{\circ} \mathrm{C}$. After 24 hours, the homografts were transferred to $-80{ }^{\circ} \mathrm{C}$ and stored for at most one-year. Preoperatively, the homografts were thawed at $4{ }^{\circ} \mathrm{C}$ for twenty-four hours and rinsed in $0.9 \% \mathrm{NaCl}$ prior to implantation.

\section{Results}

\section{Perioperative outcomes and survival}

Between June 2019 and August 2020, 17 sheep weighing $55 \pm 9 \mathrm{~kg}$ (range, 43.1-69.4 kg) were operated on, of which ten $(58.8 \%)$ survived past the first postoperative day. While 

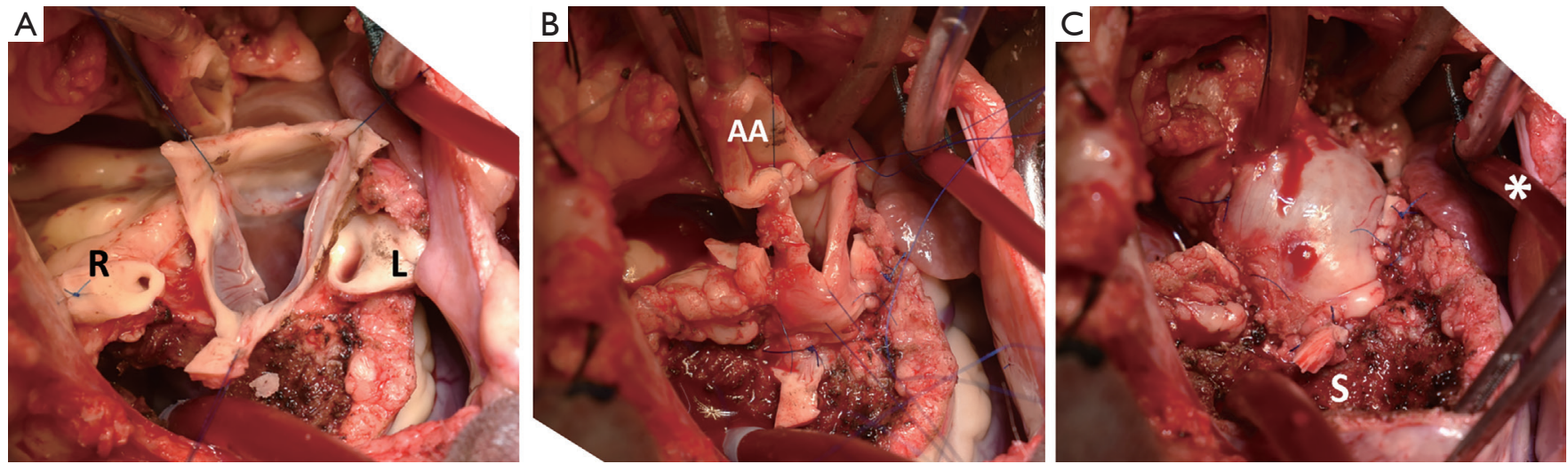

Figure 2 Intraoperative view of the aortic root. (A) Preparation of the aortic annulus. (B) Performing the distal autograft anastomosis. (C) In this animal, $1 \mathrm{~cm}$ of pulmonary artery was left distal to the sinotubular junction. Immediate dilatation is observed after the cross-clamp is released. AA, ascending aorta; L, left coronary artery; R, right coronary artery; S, interventricular septum. *,venting cannula.

one animal died on postoperative day one from bleeding, six animals were euthanized on the operating table, several hours after completion of the procedure, as their chances of survival were deemed unacceptably low. Underlying causes were brain death due to prolonged hypotension during CPB $(n=2)$, multifactorial deterioration with hypoxia, progressively increasing lactate and need for inotropes, presumably related to aspiration of gastric contents $(n=2)$, ventricular failure due to insufficient cardioprotection $(\mathrm{n}=1)$ and increasing lactate and need for inotropes after a procedure complicated by bleeding $(n=1)$. For the ten sheep surviving past the first postoperative day, operative, CPB and cross-clamp times were $242 \pm 31,106 \pm 14$ and $49 \pm 9$ minutes, respectively. Of these, one animal collapsed three weeks postoperatively during abdominal paracentesis. Autopsy revealed a dilated right ventricle with signs of myocardial infarction and patent coronary orifices; therefore, presumably related to embolisation. The nine remaining sheep recovered well postoperatively without signs of infection or cardiac decompensation and returned to the farm while awaiting follow-up studies.

Nine animals completed the study's six month followup period. One of them was sent back to our animal laboratory at five months postoperatively due to anorexia and pyrexia. Blood cultures were taken, intravenous fluids were administered for three days via a central venous catheter in the right external jugular vein and broadspectrum antibiotics were initiated, including gentamycin $5 \mathrm{mg} / \mathrm{kg}$, enrofloxacine $5 \mathrm{mg} / \mathrm{kg}$ and ceftiofur $3 \mathrm{mg} / \mathrm{kg}$ once daily via intramuscular administration. Transthoracic echocardiography showed moderate to severe pulmonary regurgitation and vegetations on the pulmonary homograft leaflets. After five days, blood cultures were positive for Enterobacter cloacae sensitive to fluoroquinolones and ceftriaxone, confirming the diagnosis of infective endocarditis. Antibiotic therapy was continued with enrofloxacin and ceftiofur. The animal recovered well, resumed its normal behavior and survived until study completion. Autopsy showed destruction of the pulmonary homograft leaflets and multiple vegetations.

\section{Magnetic resonance imaging}

Of the ten animals surviving past the first postoperative day, nine exhibited at most trivial aortic or pulmonary regurgitation with normal ventricular function on all of their postoperative MRI scans. The one sheep that developed infective endocarditis of the pulmonary homograft had moderate to severe pulmonary regurgitation and a dilated right ventricle at 5 months postoperatively. All coronary orifices appeared patent. At one week postoperatively, the pulmonary autograft approximated the shape and dimension of the native aortic root, as illustrated in Figure 3. In one sheep, septal hypokinesia was observed, consistent with perioperative trauma of a septal perforator artery.

\section{Macroscopic evaluation at autopsy}

At autopsy, the pulmonary autograft appeared viable with intact leaflets and no evidence of malcoaptation, as shown in Figure 4A. The homograft wall, on the contrary, was thin 

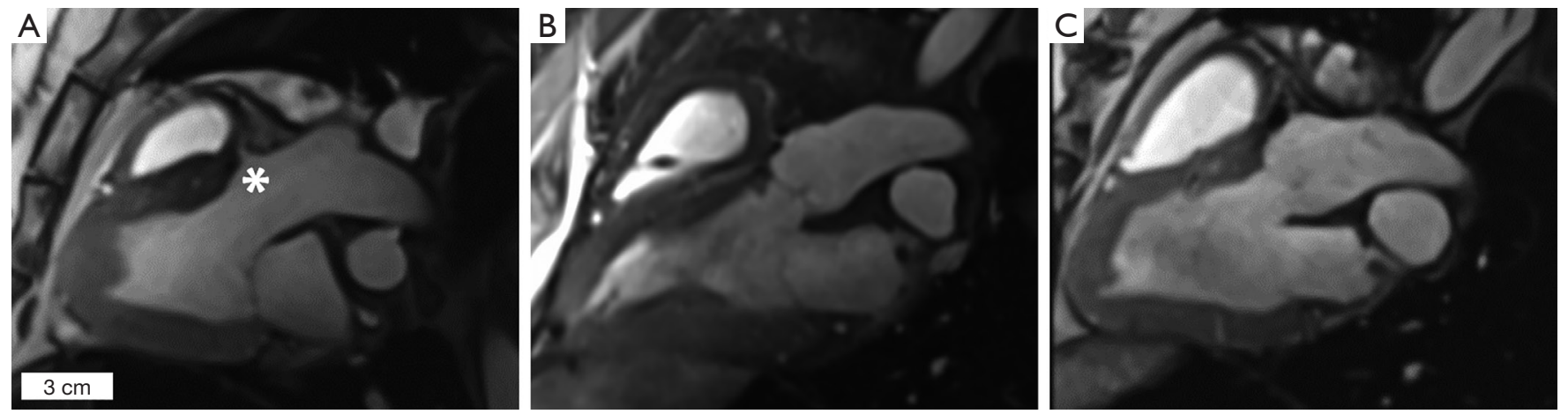

Figure 3 End-diastolic MRI images through the right coronary sinus of the same sheep $\left(^{*}\right)$. (A) Aortic root preoperatively. (B) At one week postoperatively, the autograft resembles the preoperative aorta. (C) Three months postoperatively.
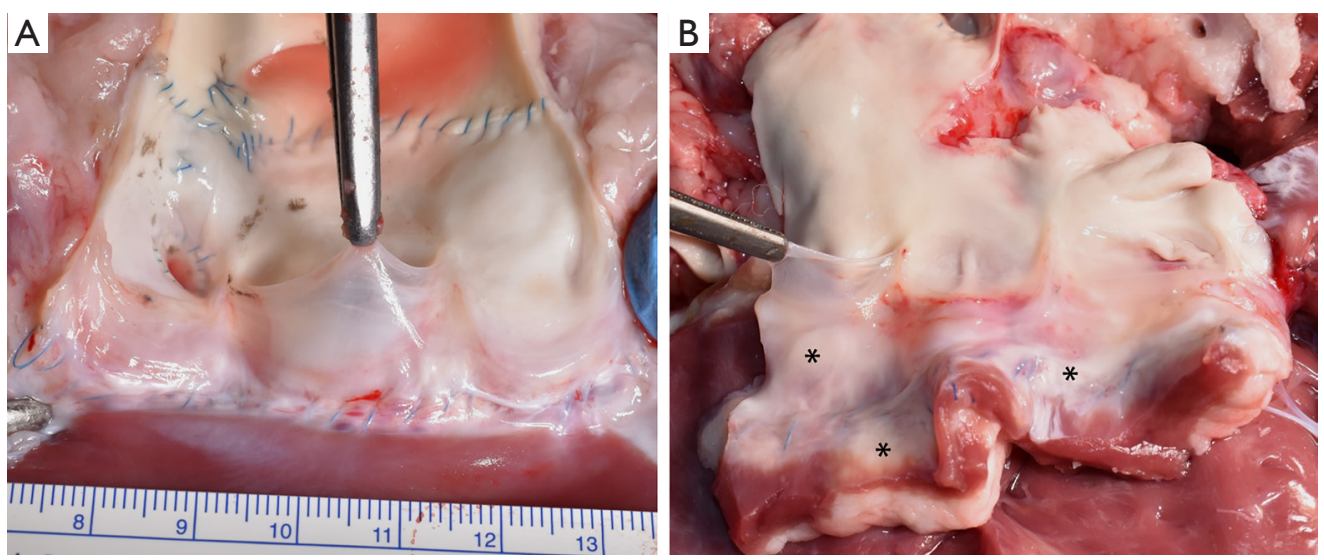

Figure 4 Representative images of the pulmonary autograft and of the homograft. (A) Pulmonary autograft as seen during explantation six months postoperatively. In this animal, $1.5 \mathrm{~cm}$ of pulmonary artery was left distal to the sinotubular junction. (B) Pulmonary homograft with fragile wall, thin leaflets and extensive fibrosis $\left(^{*}\right)$ at proximal anastomosis.

with calcification in the proximal anastomosis and delicate, translucent leaflets (Figure 4B). Three sheep had small granular deposits on the pulmonary homograft leaflets, suggestive of thrombotic formations. Besides the one sheep with clinical signs of endocarditis and extensive leaflet destruction, one other sheep had small vegetations on the pulmonary homograft at autopsy.

\section{Histological evaluation}

Microscopically, we observed viable autograft leaflets with preserved cellularity and extensive neo-vascularization at their proximal insertion (Figure 5). The leaflets of the pulmonary homograft, on the contrary, were virtually acellular. While the overall architecture of the autograft wall was preserved without significant loss of smooth muscle cells (SMCs), a portion of the elastic fibers in the tunica media appeared frayed. Furthermore, collagen deposition was observed in the tunica adventitia.

\section{Discussion}

We have presented our animal model of the Ross procedure as a freestanding root replacement, a technically demanding heart operation. The specific ovine anatomy and setting of an animal laboratory mandated several modifications in surgical strategy. Due to the specific rotational position of the sheep's heart, a left thoracotomy in the third intercostal space (Figure 1) provides access to both atrial appendages, the pulmonary artery and the ascending and descending 

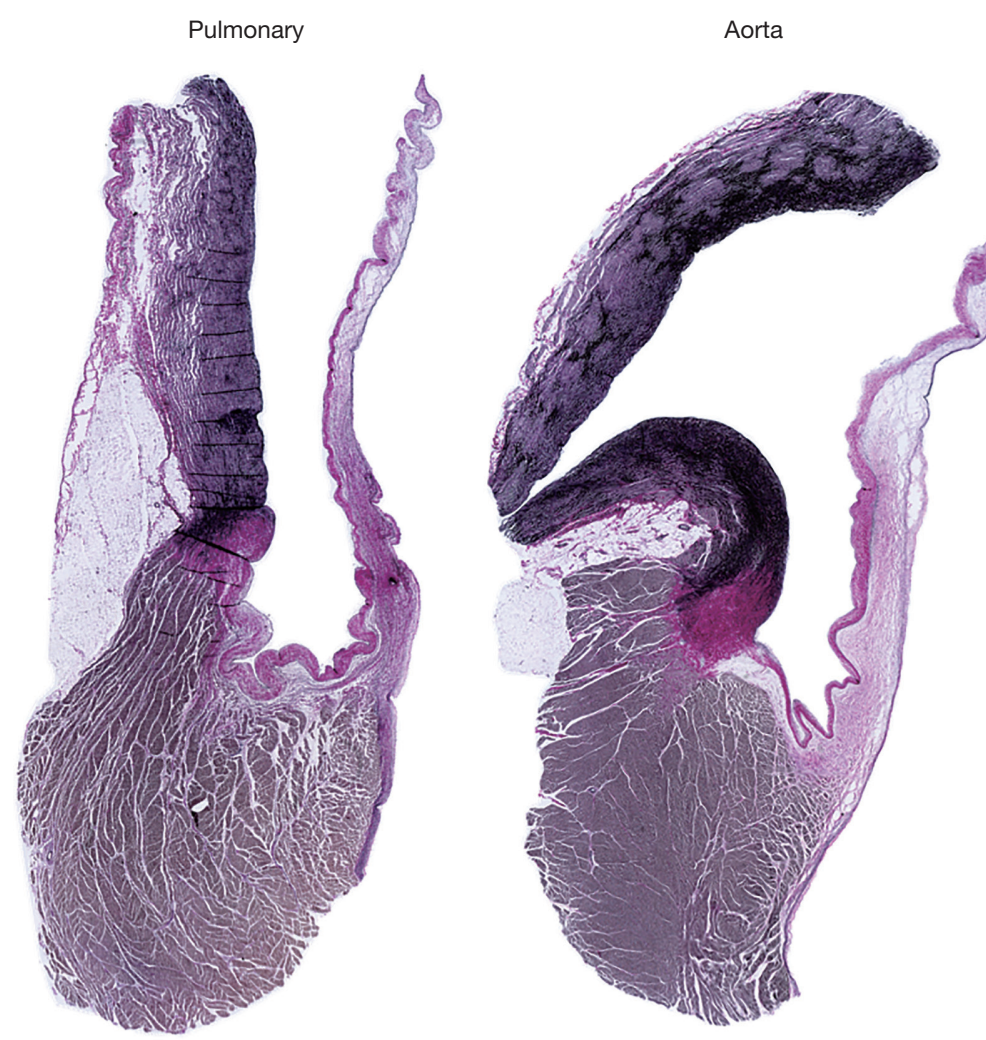

Figure 5 Representative longitudinal sections through the sinus and leaflets of the pulmonary artery and aorta of a non-operated sheep. Also shown are the pulmonary autograft and homograft at six months postoperatively in a sheep who underwent the Ross procedure. Neovascularization in the base of the pulmonary autograft leaflet and fibrosis on the adventitial side of the sinus. The arterial wall and leaflet of the pulmonary homograft are thin and acellular. Elastica Von Gieson staining.

aorta (19). This approach minimizes wound complications in these animals who rest in sternal recumbency, and has been our choice for valve surgery and procedures on the proximal descending aorta.

As sheep have a very short ascending aorta, bifurcating into the brachiocephalic trunk and descending aorta, it can be challenging to cannulate the ascending aorta and place a cross-clamp while maintaining a comfortable working space (19). Furthermore, sheep have very large external jugular veins, draining most of the blood from the head and upper limbs. While others have described cannulation of the descending aorta and right atrium, we routinely cannulate the left carotid artery and external jugular vein for valve surgery in sheep $(19,22,31)$. Cerebral perfusion is preserved through a well-developed Circle of Willis (33) and can be monitored by invasive blood pressure measurement in the contralateral auricular artery.

We harvested the pulmonary autograft on the beating heart and implanted the pulmonary homograft during reperfusion, an approach previously used by Schoof et al. $(29,30)$. Thereby, we achieved a low average cross-clamp time of $49 \pm 9$ minutes, compared to $123-138$ minutes in large clinical series for the freestanding Ross $(7,11,12)$. This reduction in cross-clamp time is especially useful in an experimental setting with limited options for postoperative monitoring and support. Using this approach, dissection between the left-facing sinus and the left main coronary artery is the most challenging aspect of the procedure. Fortunately, as the aortopulmonary continuity is not pronounced in sheep, the dissection towards the posterior pulmonary ventriculo-arterial junction is rather straightforward. Establishing excellent venous drainage using a multistage venous cannula was crucial in facilitating autograft harvesting and reducing operative mortality.

Consistently achieving reliable echocardiography images in sheep can be challenging due to the shape of their chest, 
extensive gas content of their intestines and postoperative fluid collections. Transesophageal echocardiography can be used to overcome these limitations or a rib can be excised at surgery to create a window for echocardiography (34). Prior to autopsy, we performed transthoracic echocardiography to view the pulmonary homograft, situated close to the chest wall. To visualize the pulmonary autograft, we performed transdiaphragmatic echocardiography via a small laparotomy. As it allows for simultaneous assessment of autograft dilatation, valve function and flow patterns, we elected to use MRI as the primary imaging modality. Importantly, we waited at least ten days postoperatively, as we have found that animals must have recovered sufficiently from surgery to tolerate additional anesthesia.

To achieve similar early dilatation as in adult patients, we used yearling sheep, which would also be more resilient to surgery than lambs. Indeed, we observed moderate autograft dilatation, as illustrated in Figure 3. Analogous to previous animal models of the freestanding Ross, we noted neo-vascularization in the base of the leaflets, preserved cellularity and typical pulmonary artery wall structure with adventitial collagen deposition in three sheep at six months postoperatively (29-31). Therefore, the described animal model can be used to study autograft remodeling by including detailed histological evaluation, analysis of gene transcription, serial imaging and evaluation of the autograft's biomechanical properties. Furthermore, this model would be suited to assess novel strategies for external support and their effect on histology, aortic root compliance and leaflet stress distribution (35).

\section{Limitations}

As there is no ovine model of bicuspid valve with either aortic stenosis or regurgitation, we performed the Ross procedure in healthy animals with normal aortic valve and ventricular function preoperatively. Previous studies have described ovine aortic valve cusps to be thinner and more compliant than those of pigs and elderly humans $(36,37)$. Similarly, the ovine pulmonary arterial wall may be less stiff than in humans (38). While this may simply be related to differences in hemodynamic demands, it might impact the extrapolation of data from an ovine model to the clinical situation. As this high-mortality model was deemed inappropriate to study, for example, decellularized homografts, we developed a simplified protocol for homograft preparation. While we observed no adverse effects on surgical handling, the homografts we used may not be representative of the clinical situation. The thrombotic depositions observed on the homograft leaflets in three sheep were similar in appearance to those described by Baraki et al. (34).

\section{Conclusions}

While the Ross procedure is able to restore the longterm survival of many patients by providing a living-valve substitute, the durability of the pulmonary autograft can be further improved. Therefore, large animal models remain essential. We have presented the technical details of our ovine model of the Ross procedure with promising opportunities to determine the ideal conditions for longterm autograft remodeling and valve function.

\section{Acknowledgments}

The authors would like to thank Mieke Ginckels, Nina Vanden Driessche, David Célis, Roxane Menten and the animal care takers of the KU Leuven Animal Research Center for their indispensible support throughout this project. We thank the KU Leuven Zootechnical Center for their dedication to providing the animals used for these experiments. Furthermore, none of the described experiments would have been possible without the continuous and ongoing support of the Department of Clinical Perfusion, University Hospitals Leuven. We thank the following colleagues for their technical support: Dr. Katrien Vandendriessche, Dr. Michaela Orlitova, Dr. PeterWilliam Hellings and Dr. Taisuke Shibuya. We thank our colleagues from Urogenital, Abdominal and Plastic surgery, Department of Development and Regeneration, for supplying the animals we used to create pulmonary homografts.

Funding: The described work was supported by a $\mathrm{KU}$ Leuven research project (C2 project: C24/16/026 ZKD1128-00-W01) and by a grant from the Fund for Cardiac Surgery (grant number 489661). LVH is the holder of a predoctoral grant "Strategic basic research" (SB $1 S 70220 N$ ) from the Research Foundation Flanders (FWO).

\section{Footnote}

Conflicts of Interest: The authors have no conflicts of interest to declare.

Open Access Statement: This is an Open Access article 
distributed in accordance with the Creative Commons Attribution-NonCommercial-NoDerivs 4.0 International License (CC BY-NC-ND 4.0), which permits the noncommercial replication and distribution of the article with the strict proviso that no changes or edits are made and the original work is properly cited (including links to both the formal publication through the relevant DOI and the license). See: https://creativecommons.org/licenses/by-nc-nd/4.0/.

\section{References}

1. Somerville J. The origins of the Ross operation. Images Paediatr Cardiol 2012;14:3-5.

2. Lower RR, Stofer RC, Shumway NE. Autotransplantation of the pulmonic valve into the aorta. J Thorac Cardiovasc Surg 1960;39:680-7.

3. Pillsbury RC, Shumway NE. Replacement of the aortic valve with the autologous pulmonic valve. Surg Forum 1966;17:176-7.

4. Ross DN. Replacement of Aortic and Mitral Valves With a Pulmonary Autograft. Lancet 1967;2:956-8.

5. Etnel JRG, Grashuis P, Huygens SA, et al. The Ross Procedure: A Systematic Review, Meta-Analysis, and Microsimulation. Circ Cardiovasc Qual Outcomes 2018;11:e004748.

6. El-Hamamsy I, Eryigit Z, Stevens LM, et al. Longterm outcomes after autograft versus homograft aortic root replacement in adults with aortic valve disease: A randomised controlled trial. Lancet 2010;376:524-31.

7. Sievers HH, Stierle U, Charitos EI, et al. A multicentre evaluation of the autograft procedure for young patients undergoing aortic valve replacement: Update on the German Ross Registry. Eur J Cardiothorac Surg 2016;49:212-8.

8. Mazine A, El-Hamamsy I, Verma S, et al. Ross Procedure in Adults for Cardiologists and Cardiac Surgeons. J Am Coll Cardiol 2018;72:2761-77.

9. Sievers HH, Stierle U, Petersen M, et al. Valve performance classification in 630 subcoronary Ross patients over 22 years. J Thorac Cardiovasc Surg 2018;156:79-86.e2.

10. Skillington PD, Mokhles MM, Takkenberg JJM, et al. The Ross procedure using autologous support of the pulmonary autograft: Techniques and late results. J Thorac Cardiovasc Surg 2015;149:S46-52.

11. Martin E, Mohammadi S, Jacques F, et al. Clinical Outcomes Following the Ross Procedure in Adults: A 25-Year Longitudinal Study. J Am Coll Cardiol
2017;70:1890-9.

12. David TE, Ouzounian M, David CM, et al. Late results of the Ross procedure. J Thorac Cardiovasc Surg 2019;157:201-8.

13. Yacoub MH, Tsang V, Sarathchandra P, et al. Long-term adaptive versus maladaptive remodelling of the pulmonary autograft after the Ross operation. Eur J Cardiothorac Surg 2020;57:977-85.

14. Stoney WS. Evolution of cardiopulmonary bypass. Circulation 2009;119:2844-53.

15. Nguyen K, Strauch JT, Srivastava S, et al. Orthotopic mitral valve replacement with autologous pulmonary valve in a porcine model. J Thorac Cardiovasc Surg 2004;127:1527-9.

16. Lower RR, Stofer RC, Shumway NE. Total excision of the mitral valve and replacement with the autologous pulmonic valve. J Thorac Cardiovasc Surg 1961;42:696-702.

17. Flameng W, Hermans $\mathrm{H}$, Verbeken E, et al. A randomized assessment of an advanced tissue preservation technology in the juvenile sheep model. J Thorac Cardiovasc Surg 2015;149:340-5.

18. Verbrugghe P, Verhoeven J, Clijsters M, et al. Creation of Abdominal Aortic Aneurysms in Sheep by Extrapolation of Rodent Models: Is It Feasible? Ann Vasc Surg 2018;52:225-36.

19. DiVincenti L Jr, Westcott R, Lee C. Sheep (Ovis aries) as a model for cardiovascular surgery and management before, during, and after cardiopulmonary bypass. J Am Assoc Lab Anim Sci 2014;53:439-48.

20. Pohlmann JR, Akay B, Camboni D, et al. A low mortality model of chronic pulmonary hypertension in sheep. J Surg Res 2012;175:44-8.

21. Nappi F, Spadaccio C, Castaldo C, et al. Reinforcement of the pulmonary artery autograft with a polyglactin and polydioxanone mesh in the Ross operation: experimental study in growing lamb. J Heart Valve Dis 2014;23:145-8.

22. Nappi F, Spadaccio C, Fouret P, et al. An experimental model of the Ross operation: Development of resorbable reinforcements for pulmonary autografts. J Thorac Cardiovasc Surg 2015;149:1134-42.

23. Nappi F, Spadaccio C, Fraldi M, et al. A composite semiresorbable armoured scaffold stabilizes pulmonary autograft after the Ross operation: Mr Ross's dream fulfilled. J Thorac Cardiovasc Surg 2016;151:155-64.e1.

24. Nappi F, Carotenuto AR, Di Vito D, Spadaccio C, Acar C, Fraldi M. Stress-shielding, growth and remodeling of pulmonary artery reinforced with copolymer scaffold and transposed into aortic position. Biomech Model 
Mechanobiol 2016;15:1141-57.

25. Vanderveken E, Vastmans J, Verbelen T, et al. Reinforcing the pulmonary artery autograft in the aortic position with a textile mesh: a histological evaluation. Interact Cardiovasc Thorac Surg 2018;27:566-73.

26. Vastmans J, Fehervary H, Verbrugghe P, et al. Biomechanical evaluation of a personalized external aortic root support applied in the Ross procedure. J Mech Behav Biomed Mater 2018;78:164-74.

27. Famaey N, Vastmans J, Fehervary H, et al. Numerical simulation of arterial remodeling in pulmonary autografts. Zeitschrift für Angewandte Mathematik und Mechanik 2018;98:2239-57.

28. Vanderveken E, Vastmans J, Claus P, et al. Mechanobiological adaptation of the pulmonary artery exposed to systemic conditions. Sci Rep 2020;10:2724.

29. Schoof PH, Hazekamp MG, van Wermeskerken GK, et al. Disproportionate enlargement of the pulmonary autograft in the aortic position in the growing pig. J Thorac Cardiovasc Surg 1998;115:1264-72.

30. Schoof PH, Gittenberger-de Groot AC, De Heer E, et al. Remodeling of the porcine pulmonary autograft wall in the aortic position. J Thorac Cardiovasc Surg 2000;120:55-65.

31. Tudorache I, Theodoridis K, Baraki H, et al. Decellularized aortic allografts versus pulmonary autografts for aortic valve replacement in the growing sheep model: Haemodynamic and morphological results at 20 months after implantation. Eur J Cardiothorac Surg 2016;49:1228-38.

32. Mazine A, Ghoneim A, El-Hamamsy I. The Ross Procedure: How I Teach It. Ann Thorac Surg 2018;105:1294-8.

33. Baldwin BA, Bell FR. The anatomy of the cerebral circulation of the sheep and ox. The dynamic distribution of the blood supplied by the carotid and vertebral arteries to cranial regions. J Anat 1963;97:203-15.

34. Baraki H, Tudorache I, Braun M, et al. Orthotopic replacement of the aortic valve with decellularized allograft in a sheep model. Biomaterials 2009;30:6240-6.

35. Oechtering TH, Frydrychowicz A, Sievers HH. Malrotated sinus vortices in straight graft valve-sparing aortic root treatment: A matter of concern? J Thorac Cardiovasc Surg 2017;154:794-7.

36. Martin C, Sun W. Biomechanical characterization of aortic valve tissue in humans and common animal models. J Biomed Mater Res A 2012;100:1591-9.

37. Sands MP, Rittenhouse EA, Mohri H, Merendino KA. An Anatomical Comparison of Human, Pig, Calf, and Sheep Aortic Valves. Ann Thorac Surg 1969;8:407-14.

38. Cabrera MS, Oomens CWJ, Bouten CVC, et al. Mechanical analysis of ovine and pediatric pulmonary artery for heart valve stent design. J Biomech 2013;46:2075-81.
Cite this article as: Van Hoof L, Claus P, Jones EAV, Meuris B, Famaey N, Verbrugghe P, Rega F. Back to the root: a large animal model of the Ross procedure. Ann Cardiothorac Surg 2021;10(4):444-453. doi: 10.21037/acs-2020-rp-21 